\title{
A absorção dos egressos de Contabilidade no mercado de trabalho: um estudo do curso de Ciências Contábeis da Universidade Estadual do Sudoeste da Bahia ${ }^{1}$
}

\author{
Glarcy Sampaio de Almeida \\ Manoel Antonio Oliveira Araújo ${ }^{3}$ \\ Danilo Moreira Jabur ${ }^{4}$
}

\begin{abstract}
Resumo: $\mathrm{O}$ presente trabalho tem o objetivo de verificar a absorção dos egressos no mercado de trabalho em contabilidade. A questão-problema apresentada é a seguinte: Qual a situação acadêmico-profissional-financeira dos egressos do curso de Ciências Contábeis da UESB, formados no período entre 1997 e 2001? A escolha desse tema para os pesquisadores justifica-se porque o estudo amplia o conhecimento na área de formação, possibilita a análise do próprio mercado de trabalho e também se presta para crescimento intelectual dos profissionais envolvidos. A pesquisa realizada adotou como instrumento de coleta de dados a entrevista, com levantamento de nomes dentro da própria instituição para a localização dos egressos. Os resultados mostraram a importância da capacitação do egresso para o mercado de trabalho e como eles estão atuando dentro desse contexto.
\end{abstract}

Palavras-chave: Contabilidade. Egressos. Profissional de Contabilidade.

Resumen: El tema de esta investigación es Educación Contable, con énfasis en los egresados. Así el presente trabajo tiene como objetivo: 1. Identificar la absorción de los egresados en el mercado de trabajo en contabilidad. La cuestión-problema presentada es la siguiente: ¿Cuál es la situación académico-profesional-financiera de los egresados formados de 1997 a 2001 del curso de Ciencias Contables de la UESB? La elección de este tema para la investigadora se justifica por ampliar el conocimiento en el área de formación, por la satisfacción personal, también promoverla en el mercado de trabajo, mientras que para el profesional servirá de crecimiento intelectual. La investigación realizada adoptó como instrumento de recolección de datos la entrevista con levantamiento de nombres dentro de la propia institución para la localización de los egresados. Los resultados mostraron la importancia de la capacitación del egresado para el mercado de trabajo y cómo están actuando dentro de ese contexto.

Palabras clave: Contabilidad. Egresados. Profesional de Contabilidad.

\footnotetext{
${ }^{1}$ Este artigo é parte integrante da monografia intitulada Estudo com ênfase nos egressos do curso de Ciências Contábeis da Universidade Estadual do Sudoeste da Babia, apresentada no dia 26 de novembro de 2018, do curso de Ciências Contábeis, no campus de Vitória da Conquista-Ba.

${ }^{2}$ Estudante do Curso de Ciências Contábeis da UESB. Membro do grupo de pesquisa em Educação Contábil da UESB. E mail: glarcy_sampaio@hotmail.com

${ }_{3}^{3}$ Doutor em Educação pela PUC-SP, Professor Adjunto da Universidade Estadual do Sudoeste da Bahia (UESB). E-mail: maoaraujo1994@gmail.com.

${ }^{4}$ Mestre em Inovação e Tecnologia pela Universidade Estadual de Santa Cruz (UESC). E-mail: djabur@gmail.com.
}

Página 109 Caderno de Ciências Sociais Aplicadas, Vitória da Conquista/BA, vol. 16, n 27, ano 16, p. 109-129, jan/jun 2019. 


\section{Introdução}

Geralmente, entre os motivos que influenciam a escolha do curso de Ciências Contábeis, o que mais se destaca é o desejo de ingressar na vasta área contábil (MARION, 2005). Porém, ao término do curso as instituições de ensino não fazem o acompanhamento de seus egressos, para registrar as suas experiências ao se inserirem no mercado de trabalho e seus investimentos em atividades complementares em educação continuada.

Assim, este trabalho tem por finalidade investigar como está a situação acadêmico-profissionalfinanceira dos egressos do curso de Ciências Contábeis da UESB de Vitória da Conquista. As informações obtidas com base nessa pesquisa serão muito importantes, tanto para a Instituição de Ensino Superior (IES), quanto para os discentes que investem nessa área de formação.

Com o término do curso, os egressos, em tese, estariam aptos a ingressar no mercado de trabalho e atuar nas diversas áreas possíveis, devido à sua formação. Todavia, sem o contato e sem informações pertinentes desses egressos, não é possível ter um panorama para verificar a situação profissional do acadêmico.

A ênfase do presente estudo nos egressos proporciona grandes perspectivas profissionais aos seus discentes de atuar em várias áreas: contador de empresa pública e privada, auditor, pesquisador, consultor, professor entre outras, porém não fornece a comunidade acadêmica nenhuma informação sobre a realidade para se inserir e permanecer no mercado de trabalho, dessa forma surge à necessidade de analisar se os egressos estão atuando no mercado de trabalho ou não.

A escolha desse tema para a pesquisadora justifica-se porque o estudo amplia o conhecimento na área de formação, possibilita a análise do próprio mercado de trabalho e também se presta para o crescimento intelectual dos profissionais envolvidos.

Essa pesquisa, Educação Contábil, com ênfase nos egressos, tem como objetivo identificar a absorção dos egressos no mercado de trabalho em contabilidade.

Um acompanhamento adequado da condição profissional-financeira dos egressos é uma forma de avaliar o curso e de se pensar em metodologias que atendam às exigências do mercado de trabalho, bem como aos desafios da profissão e suas perspectivas.

É imprescindível também que, após concluírem a graduação do curso de Ciências Contábeis, os alunos conheçam a realidade do mercado de trabalho, e, dessa forma, possam se aperfeiçoar nas suas habilidades, de acordo com as exigências do mercado de trabalho. Outro ponto relevante da pesquisa é

Página 110 Caderno de Ciências Sociais Aplicadas, Vitória da Conquista/BA, vol. 16, n 27, ano 16, p. 109-129, jan/jun 2019. 
que ela viabiliza a apreensão do nível de preparação dos concluintes, em contraponto aos seus concorrentes, situação que pode viabilizar maior êxito na ocasião em que os formandos forem competir no mercado de trabalho para Contadores.

A situação problema apresentada é a seguinte: Qual a situação acadêmico-profissional-financeira dos egressos formados de 1997 a 2001 do curso de Ciências Contábeis da UESB?

Já a hipótese levantada nessa pesquisa afiança que a situação acadêmico-profissional-financeira dos egressos formados de 1997 a 2001 do curso de Ciências Contábeis da UESB é satisfatória.

A pesquisa relaciona vários autores importantes, entre eles pode-se destacar Marion (2007) e Iúdicibus (2002), Bardin (2011). Com relação aos procedimentos foi necessário recorrer ao estudo bibliográfico; o instrumento de coleta de dados utilizado foi a entrevista, com levantamento de nomes dentro da própria instituição para a localização dos egressos.

O estudo adotou uma abordagem qualitativa, priorizando mais os conceitos do que a quantidade, objetivando explorar o conhecimento de cada entrevistado. Tal opção está assentada no entendimento de que os estudos que empregam uma metodologia qualitativa podem descrever a complexidade de determinado problema, analisar a interação de certas variáveis, compreender e classificar processos dinâmicos vividos por grupos sociais (RICHARDSON, 1999).

Os resultados mostraram que o mercado de trabalho é bastante promissor, com oportunidades de atuação em diversas áreas, podendo o profissional de contabilidade atuar em empresas, ou de forma independente como autônomo, como também no ensino e em órgão público. Também se verifica a importância da capacitação do egresso para o mercado de trabalho e como eles estão atuando dentro desse contexto.

\subsection{Referencial teórico}

Com o entendimento de que a estratégia da pesquisa aplicada deve estar devidamente clara, permitindo aos usuários o fácil acesso ao estudo empreendido, coaduna-se que, verbis, "No referencial teórico é onde se discutem os diferentes pontos de vista de autores diferentes sobre o mesmo assunto. Ele se consiste em expor as ideias e com o intuito de fazer com que os leigos absorvam o máximo de conteúdo possível” (LOPES, 2006).

De tal modo, apresenta-se a seguir o referencial teórico, que embasa o tema específico proposto no presente estudo.

Página 111 Caderno de Ciências Sociais Aplicadas, Vitória da Conquista/BA, vol. 16, n 27, ano 16, p. 109-129, jan/jun 2019. 


\subsection{Marco conceitual}

\subsubsection{Conceito de Contabilidade}

Contabilidade é um sistema de informação que identifica, registra e comunica os eventos econômicos de uma entidade aos usuários interessados (SILVA, 2009). Também conhecida como ciência da riqueza humana, é o instrumento que auxilia os gestores na tomada de decisões, pois tem como objetivo principal "gerar e fornecer informações contábeis a respeito dos patrimônios das entidades de forma útil e relevante para que seus usuários possam tomar decisões” (HOSS et al., 2008 pg.12).

\subsubsection{O profissional de contabilidade}

O profissional de contabilidade é aquele que possui competências e habilidades diversificadas, as quais lhe permitirão uma posição executiva chave, de forma que haja um gerenciamento do planejamento de todas as subdivisões da empresa. De tal modo, o profissional de contabilidade atua como um consultor gerencial que fornece informações relevantes aos gestores para suas decisões, desempenha suas funções de maneira muito especial, ao organizar e reportar dados relevantes, entender, manejar e criticar métodos, instrumentos e pesquisas e analise e forma de exercer uma influência, que induz os gerentes a tomarem decisões lógicas e consistentes com a missão e objetivos da empresa (SANTOS; SOUZA, 2010).

Marion (2005) sugere que o contador deve ser o profissional mais bem informado de toda empresa, pois sua atuação exige que conheça as operações realizadas, faça seu registro e apresente as informações resultantes do processo contábil na forma de relatórios para administração da empresa, para que esta possa tomar decisões. As decisões tomadas, por sua vez, podem ocasionar retornos positivos ou negativos para a empresa e influenciar quem dela depende; nessas circunstâncias, o contador assume verdadeiramente uma responsabilidade social.

Oliveira e Silva (2014), por sua vez, destacam que o papel do novo profissional de contabilidade deve expandir as suas competências, dominar tecnologias, ter capacidade de trabalhar em grupo, liderar, comunicar-se, saber trabalhar em equipe, já que o profissional de contabilidade deve desenvolver outras funções, seja na empresa, ou até mesmo em órgão públicos, no ensino, ou como profissional liberal. Dessa forma, é importante destacar que o profissional de contabilidade não é aquele que atua

Página 112 Caderno de Ciências Sociais Aplicadas, Vitória da Conquista/BA, vol. 16, n 27, ano 16, p. 109-129, jan/jun 2019. 
exclusivamente dentro da organização na função de contador, mas deve estar apto a exercer outras funções nas organizações.

O profissional de contabilidade deve ser também capaz desenvolver outras atribuições, seja nas empresas, no ensino, em órgãos públicos e também como profissional liberal. Assim expôs Marion (2007), em uma síntese das principais ocupações dos profissionais da área contábil, informações que foram sucintamente reunidas de acordo com o quadro abaixo:

Quadro 2: Ocupações em que o profissional da área contábil pode atuar.

\begin{tabular}{|l|l|l|l|}
\hline ENSINO & EMPRESAS & $\begin{array}{l}\text { PROFISSIONAL } \\
\text { LIBERAL }\end{array}$ & $\begin{array}{l}\text { ÓRGÃOS } \\
\text { PÚBLICOS }\end{array}$ \\
\hline Professor & Assistente Contábil & Auditor Independente & Contador Público \\
\hline Pesquisador & Analista Financeiro & Consultor & Auditor Fiscal \\
\hline Escritor & Contador Geral & Empresário & Diversos \\
\hline Parecerista & Cargos Administrativos & Perito Contábil & Tribunal de Contas \\
\hline Conferencista & Auditoria & $\begin{array}{l}\text { Investigador } \\
\text { Fraudes }\end{array}$ & Controladoria Pública \\
\hline & Atuário & Árbitro & \\
\hline
\end{tabular}

Fonte: Adaptado de Marion (2007, p. 35).

A nova era do meio contábil chegou e com ela a transformação dos profissionais. Não basta apenas lançar números, contas em balanços e escriturar livros. De sua função técnica, o contador passou a principal fornecedor de informações verídicas e confiáveis e, nesse novo contexto, o profissional se viu diante de um novo modo de trabalhar, onde precisa estar ligado a toda uma gama de novas funções inerentes a esse novo profissional (OLIVEIRA et.al 2016).

\subsubsection{Conceito de Contabilidade e de Educação}

Em um sentido mais amplo, educação constitui o meio em que os hábitos, costumes e valores de uma identidade são transferidos de uma geração para a geração seguinte. A educação vai se desenvolvendo por intermédio de situações presenciadas e experiências convividas pelo sujeito ao longo da sua vida. Para Brandão (2005), a educação envolve o poder, a riqueza e a troca de símbolos presentes em cada sociedade.

A educação, como um acontecimento social-histórico-cultural, abrange uma gama de ambientes e de pessoas, podendo ser infundida de pai para filho, ou de anciãos a aprendizes, de professores a alunos, de alunos a alunos, e isso independentemente do sexo, de raça ou de idade.

Página 113 Caderno de Ciências Sociais Aplicadas, Vitória da Conquista/BA, vol. 16, n 27, ano 16, p. 109-129, jan/jun 2019. 


\subsubsection{Conceito de egresso}

Egresso é definido como aquele que efetivamente concluiu os estudos, recebeu o diploma e está apto a ingressar no mercado de trabalho, como fator de destaque e fonte de informação à Instituição de Ensino Superior (IES) que o formou (LOUSADA; MARTINS, 2005).

No âmbito educacional, Pena (2000) relata a existência de divergências no que concerne à definição de egresso, pois segundo a autora, alguns estudiosos usam o termo egresso para referir-se exclusivamente aos alunos formados; outros abrangem a denominação a todos os indivíduos que saíram do sistema escolar por diferentes vias, sejam eles ex-alunos diplomados, por desistência, por transferência ou jubilados. Ferreira (2004) apresenta o conceito de egresso, no âmbito educacional, como sendo o indivíduo que cumpriu a grade curricular de um curso de graduação ou pós-graduação e obteve uma titulação em determinada área do conhecimento. Analisando o termo egresso contido na legislação da área educacional, entende-se aquela pessoa que efetivamente concluiu os estudos, recebeu o diploma e está apto a ingressar no mercado de trabalho (BRASIL, 1996).

\subsubsection{O mercado de trabalho para o profissional de Contabilidade}

É incontroverso que as organizações necessitam de profissionais capacitados que proporcionem conhecimento, técnica, planejamento, agilidade, eficiência e decisões fundamentais para o crescimento e a sustentabilidade dos negócios. Desse modo, a figura do profissional contábil é cada vez mais importante para a sociedade, visto que ele está diretamente ligado aos fluxos de informações necessárias para os processos decisórios da entidade (FONSECA et al., 2014).

De acordo Santos (2008), depois do fim da era de alta inflação, a partir da metade dos anos 1990, o cenário econômico passou por um período de grandes mudanças e adaptações. As empresas que foram mais ágeis em ajustar seu foco para o seu negócio principal, seu core business, e não mais gerenciar os ganhos e as receitas inflacionárias, obtiveram maior índice de sucesso.

O ambiente competitivo e a disputa dos mercados internacionais pelas organizações exigem dos contadores informações rápidas e precisas, além de responsabilidade, agilidade, habilidade de negociação e medidas corretivas para melhorar a eficiência da empresa, garantido sua sobrevivência no mercado (FONSECA et al., 2014).

É por isso que o contador deve estar sempre em processo de aprendizagem procurando se atualizar e se especializar, para que assim, execute um trabalho de precisão que gere informações aos

Página 114 Caderno de Ciências Sociais Aplicadas, Vitória da Conquista/BA, vol. 16, n 27, ano 16, p. 109-129, jan/jun 2019. 
seus usuários, contribuindo para o crescimento das organizações e da sociedade (FONSECA et al., 2014).

Também é preciso ter consciência que, nos ambientes sociais, profissionais, nas empresas e instituições públicas, é necessário seguir normas éticas, comportamento que deve prevalecer mesmo numa sociedade de culturas diversificadas. De tal modo, o indivíduo precisa compreender e seguir os regulamentos e as regras que o Código de Ética estabelece, não devendo impor as suas próprias crenças e valores, mas respeitando e pensando na coletividade (PEREIRA, 2017).

\section{Metodologia}

Para proceder a coleta de dados das entrevistas, foi necessário solicitar ao colegiado do Curso de Ciências Contábeis da UESB a relação dos nomes dos egressos do período de 1997 a 2001. Após conseguir os contatos, foram escolhidos 10 egressos que atuam e moram em Vitória da Conquista. Desses escolhidos, apenas 6 se dispuseram a participar da entrevista. Esses egressos foram contatados por meio de ligação telefônica, via e-mail e por mensagem de aplicativo.

Os egressos compareceram no dia e horário marcados para a realização das entrevistas, as quais continham questões para a análise da situação acadêmico-profissional, da inserção no mercado de trabalho e do processo de capacitação profissional na área de formação.

\subsection{Técnica de Análise de Conteúdo}

A análise de conteúdo se debruça no estudo e apreensão do conhecimento de variáveis de ordem psicológicas, sociológicas, histórica etc., por meio de um mecanismo de dedução com base em indicadores reconstruídos de uma amostra de mensagens particulares (BARDIN, 2011).

Assim, para a análise do conteúdo das entrevistas buscou-se distribuí-las em quadros, nos quais foram analisadas cada questão em comum aos 6 respondentes. Nesses quadros foram agrupadas as repetições ou incidências, parágrafo síntese e tópico de análise.

Nas repetições ou incidências foram identificadas as falas com aspectos em comum. No parágrafo síntese foram analisadas as falas com maiores incidências e no tópico de análise foi feita a separação de um todo das respostas.

Após o término dessas análises foram construídas tabelas com a ordem dos entrevistados (de 1 a 6), com a questão a ser analisada e com as repetições ou incidências para calcular as porcentagens dos índices de repetições.

Página 115 Caderno de Ciências Sociais Aplicadas, Vitória da Conquista/BA, vol. 16, n 27, ano 16, p. 109-129, jan/jun 2019. 
Com base nas porcentagens foram construídos gráficos para melhor visualizar as frações das repetições.

\subsection{Contextos da pesquisa}

A pesquisa foi realizada com os egressos da UESB, Universidade que é uma Instituição multicampi, com sede na cidade de Vitória da Conquista. O surgimento dessa instituição aconteceu a partir da política de interiorização do Ensino Superior, dominada no Plano Integral de Educação do Governo do Estado, de 1969, com a instalação das Faculdades de Formação de Professores, nos municípios de Vitória da Conquista, Jequié, Feira de Santana e Alagoinhas, que se somava à Faculdade de Agronomia do Médio São Francisco (Famesf), criada na década de 1950.

Até meados de 1960, existiam apenas duas universidades e algumas instituições de Ensino Superior isolada. O Governo Estadual demonstrava uma preocupação com a política global de acréscimo do sistema de educação em todos os níveis e, com a interiorização, procurou organizar, espacialmente, o ensino superior. A crescente expansão da rede pública estadual de ensino de $1^{\circ}$ e $2^{\circ}$ graus exigia a fixação, no interior, de pessoal qualificado para o exercício do magistério, o incentivo da pesquisa científica e a difusão de uma cultura universitária.

Em 1962, por meio da Lei no 1.802, de 25/10, são criadas as Faculdades de Filosofia, Ciências e Letras de Vitória da Conquista, Jequié, Feira de Santana, Ilhéus, Caetité e Juazeiro, procurando atender àquelas exigências. Em 1969, é criada a Faculdade de Educação de Vitória da Conquista, pelo Decreto Federal no 21.363, de 20/07. Ainda nesse ano, com a Lei no 2.741, de 11/11, a Faculdade é constituída como Autarquia. Em 1970, o Poder Executivo, autorizado pela Lei nº 2.852, de 09/11, institui a Fundação Faculdade de Educação de Jequié, denominada, posteriormente de Autarquia, pelo Decreto $\mathrm{n}^{\circ} 23.135 / 70$.

As Faculdades só teriam os funcionamentos efetivados com a implantação dos cursos de Letras, em Vitória da Conquista (1971), Ciências e Letras, em Jequié (1972), licenciaturas curtas, autorizadas, respectivamente, pelos Decretos Federais no 68.219, de 11/02/71, n 79.130, de 17/01/77 e $\mathrm{n}^{\mathrm{o}}$ 80.551, e 11/10/77. O reconhecimento dos cursos ocorreria pelo Decreto Federal $\mathrm{n}^{\circ} 79.252$, de 14/02/77 (Letras, em Vitória da Conquista), e pela Portaria Ministerial n 37, de 09/02/84 (Ciências e Letras, em Jequié).

Página 116 Caderno de Ciências Sociais Aplicadas, Vitória da Conquista/BA, vol. 16, n 27, ano 16, p. 109-129, jan/jun 2019. 


\section{Cadernos de Ciências SOCIAIS APLICADAS}

Somente em 1980 veio a falar-se em universidade, quando, pela Lei $\mathrm{n}^{\circ} 3.799$, de 23/05, o Poder Executivo instituiu uma Fundação para "criar e manter uma universidade no Sudoeste do Estado". A Fundação Educacional do Sudoeste é criada pelo Decreto no 27.450, de 12/08/80, com o objetivo de "implantar e manter uma Universidade no Sudoeste, incorporando ao seu patrimônio os bens e direitos pertencentes às Faculdades existentes em Vitória da Conquista e Jequié".

Em 1980, através da Lei Delegada nº 12, de 30/12/80, a Fundação Educacional do Sudoeste é extinta, como mantenedora da Universidade, sendo criada a Autarquia Universidade do Sudoeste. O Regulamento de Implantação dessa Universidade foi aprovado em 25/08/81, pelo Decreto no 28.169 , sendo a ela incorporadas as Faculdades de Formação de Professores, a Faculdade de Administração e outras unidades que viessem a ser instituídas e a ela vinculadas.

Com a constituição da Autarquia são implantados, também, as Escolas de Agronomia, em Vitória da Conquista, Zootecnia, em Itapetinga, e Enfermagem, em Jequié. No início de 1984, mediante convênio entre a UESB e a Fundação de Apoio à Pesquisa e Extensão (Fapex) e, sob a coordenação do Centro de Estudos Interdisciplinares para o (Setor Público ISP), da Universidade Federal da Bahia, foi elaborada a "Carta Consulta". Após dois anos de trabalho, esse documento foi entregue ao Conselho Estadual de Educação, para autorização de funcionamento da UESB, em sistema multicampi, vinculada à Secretaria de Educação e Cultura do Estado.

Em seu parecer CEE n 119/87, o Conselho opina favoravelmente e, com base nesse parecer, o Governo Federal baixa o Decreto $n^{\circ}$ 94.250, de 22/04/87, autorizando o funcionamento da Universidade. O seu credenciamento veio ocorrer em 1998, por meio do Decreto $\mathrm{n}^{\circ}$ 7.344, de 27/05/98, publicado no Diário Oficial do Estado da Bahia de 28/05/98.

O curso de Ciências Contábeis da UESB, em nível de bacharelado, obteve a primeira autorização para funcionamento no ano de 1990, emitida pelo Conselho Estadual de Educação em seu Parecer 042/90. Novamente, em 1999, foi reconhecido mediante Parecer do Conselho Estadual de Educação no 218/99. A última renovação de reconhecimento do curso ocorreu na data de 17 de janeiro de 2018, após o Decreto Estadual no 18.168, cuja validade é de 5 anos (SILVA, 2018).

Página 117 Caderno de Ciências Sociais Aplicadas, Vitória da Conquista/BA, vol. 16, n 27, ano 16, p. 109-129, jan/jun 2019. 


\section{Apresentação e análise dos dados coletados}

A análise de dados é a "tentativa de evidenciar as relações existentes entre o fenômeno estudado e outros fatores" (LAKATOS; MARCONI, 2003).

Aqui os dados serão tratados de forma mais automática possível, para preservar a informação textual original. Serão efetuados agrupamentos nos quais será feita uma partição em torno de núcleos fatuais com base em características pertinentes dos inquiridos, como idade, categoria socioprofissional, entre outras (BARDIN, 2011).

Tabela 9: Que função você ocupa atualmente no mercado de trabalho?

\begin{tabular}{l|l|l|l}
\hline Ordem & $\begin{array}{l}\text { Questão 9 - Que função você ocupa atualmente no } \\
\text { mercado de trabalho? }\end{array}$ & $\begin{array}{l}\text { Repetições } \\
\text { ou } \\
\text { incidências }\end{array}$ & Percentuais \\
\hline 01 & $\begin{array}{l}\text { Administrador, contador, advogado, consultor } \\
\text { empresarial, diretor de uma empresa de consultoria e de } \\
\text { assistência a auditoria, perícia e nas áreas administrativas } \\
\text { e contábeis, terceiro juiz arbitral de Vitória da Conquista } \\
\text { e região. }\end{array}$ & 1 & $16 \%$ \\
\hline 02 & $\begin{array}{l}\text { Servidora pública estadual e professora de instituição } \\
\text { privada. }\end{array}$ & 3 & $50 \%$ \\
\hline 03 & $\begin{array}{l}\text { No momento não estou trabalhando. } \\
\text { Ocupo a função de assessora técnica de planejamento e e } \\
\text { finanças dentro de uma estrutura. }\end{array}$ & 1 & $17 \%$ \\
\hline $04 b$ & & $17 \%$ \\
\hline
\end{tabular}

Fonte: Dados da Pesquisa elaborada pelo Autor 


\section{- CADERNOS de GIÉNCIAS SOCIAIS APLICADAS}

Gráfico 9: Função exercida atualmente no mercado de trabalho.

\section{Repetições ou incidências}

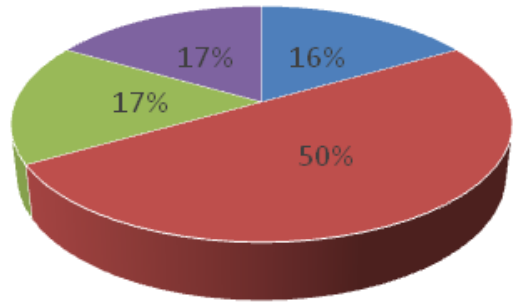

- 1 Administrador, contador, advogado, consultor empresarial, diretor de uma empresa de consultoria e de assistência a auditoria, perícia e nas áreas administrativas e contábeis, terceiro juiz arbitral de Vitória da Conquista e regiåo.

- 2 Servidora pública estadual e professora de instituição privada.

- 3 No momento não estou trabalhando.

- 4 Ocupo a função de assessora técnica de planejamento e finanças dentro de uma estrutura.

Fonte: Elaborado pela autora, 2018.

Conforme a tabela e o gráfico 9, o seguinte parágrafo-síntese da questão 9 informa: “Os entrevistados exercem a função atualmente no mercado de trabalho na área contábil em diversas áreas, tanto na área pública quanto na privada como professores”. Observa-se que no parágrafo síntese da questão anterior, a maioria dos entrevistados já atuava como professores, e após se formarem em Ciências Contábeis, preferiram entrar na área pública e privada, também como docentes. De acordo com Laffin (2005), na maioria das vezes, o professor de contabilidade é egresso do próprio curso/instituição e, entre outras atividades, também exerce a docência. 


\section{Cadernos de Ciéncias SOCIAIS APLICADAS}

Tabela 10: Em sua opinião, a instituição em que você se formou atendeu as suas expectativas diante do mercado de trabalho?

\begin{tabular}{l|l|l|l}
\hline Ordem & $\begin{array}{l}\text { Questão 10 - Em sua opinião, a instituição em que você } \\
\text { se formou, atendeu as suas expectativas diante do } \\
\text { mercado de trabalho? }\end{array}$ & $\begin{array}{l}\text { Repetições } \\
\text { ou } \\
\text { incidências }\end{array}$ & Percentuais \\
\hline 01 & $\begin{array}{l}\text { Não, eu não poderia ser demagógico, eu costumo dizer } \\
\text { que as faculdades de um modo geral, te dão uma } \\
\text { bagagem teórica e essa bagagem teórica, ela tem um } \\
\text { abismo para que você chegue ao mercado. }\end{array}$ & 2 & $33 \%$ \\
\hline 02 & $\begin{array}{l}\text { Ela lhe dar uma formação que é possível dentro das } \\
\text { condições atuais. E a partir disso, você deve buscar e } \\
\text { desenvolver que é possível. }\end{array}$ & 4 & $67 \%$ \\
\hline
\end{tabular}

Fonte: Dados da Pesquisa elaborada pelo Autor

Gráfico 10: A Expectativa dos egressos diante do mercado de trabalho.

\section{Repetições ou incidências}

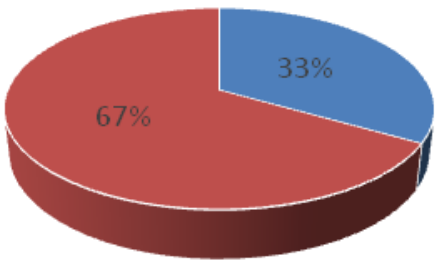

- 1 Não, eu não poderia ser demagógico, eu costumo dizer que as faculdades de um modo geral, te dão uma bagagem teórica e essa bagagem teórica, ela tem um abismo para que você chegue ao mercado.

- 2 Ela lhe dar uma formação que é possível dentro das condições atuais. E a partir disso, você deve buscar e desenvolver que é possivel.

Fonte: Elaborado pela autora, 2018.

De acordo com a tabela e o gráfico 10, e segundo os respondentes: "A maioria dos entrevistados acredita que a instituição onde formaram atendeu as suas expectativas diante do mercado de trabalho, pois colaborou com a formação possível dentro das condições atuais". Isso mostra que, de acordo com os entrevistados, o ensino oferecido pela instituição foi de qualidade e forneceu base para enfrentar o mercado de trabalho. 


\section{- Cadernos de CiêncIas SOCIAIS APLICADAS}

Tabela 11: Antes de se formar você exercia alguma outra profissão?

\begin{tabular}{l|l|l|l}
\hline Ordem & $\begin{array}{l}\text { Questão 11 - Antes de se formar você exercia alguma } \\
\text { outra profissão? }\end{array}$ & $\begin{array}{l}\text { Repetições } \\
\text { ou } \\
\text { incidências }\end{array}$ & Percentuais \\
\hline 01 & Era consultor de uma multinacional. & 1 & $16 \%$ \\
\hline 02 & Área da educação (Professor). & 2 & $33 \%$ \\
\hline 03 & Administrador. & 1 & $17 \%$ \\
\hline 04 & Técnico Administrativo. & 1 & $17 \%$ \\
\hline 05 & Servidora pública. & 1 & $17 \%$ \\
\hline
\end{tabular}

Fonte: Dados da pesquisa elaborada pelo Autor

Gráfico 11: Profissão dos egressos antes de se formar.

\section{Repetições ou incidências}

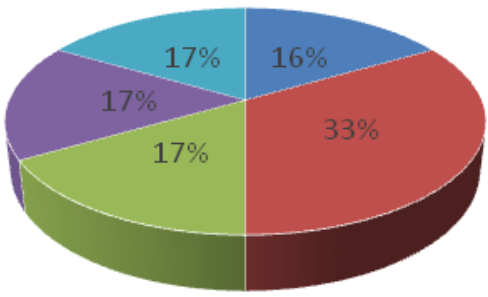

\footnotetext{
- 1 Era consultor de uma multinacional. - 2 Área da educação (Professor).

- 3 Administrador.

- 4 Técnico Administrativo.

- 5 Servidora pública
}

Fonte: Elaborado pela autora, 2018.

Em conformidade com a tabela e com o gráfico 11, um ponto que foi perguntado aos egressos foi em relação ao emprego, precisamente se antes de se formarem eles exerciam alguma profissão, ocasião em que se obteve como resposta que a maioria atuava na área da educação como professor.

É salutar registrar, o artigo publicado por Dal-Cin (2017) mostra que alguns pesquisadores se debruçaram sobre esse tema da educação superior em ciências contábeis, podendo-se citar como um deles o pesquisador Laffin (2002) que, em sua tese de doutoramento, aponta: a opção pela profissão de professor para o profissional com formação em ciências contábeis aparece como uma escolha que ocorre por situações fortuitas como convites, anúncios, conversas informais e necessidade financeira. O referido artigo constata que a atividade docente aparece como uma carreira diferente, que demanda atribuições também diferentes e que confere ao sujeito um status social que não está no exercício da atividade de contador. Por outro lado, apreende-se que esse status social de ser professor qualifica as

Página 121 Caderno de Ciências Sociais Aplicadas, Vitória da Conquista/BA, vol. 16, n 27, ano 16, p. 109-129, jan/jun 2019. 


\section{- Cadernos de Ciências SOCIAIS APLICADAS}

atividades de contador, possibilitando uma atuação mais próxima ao conhecimento teórico/prático. Entretanto, assumir a opção de ser contador oferece uma situação econômico/financeira mais favorável.

Tabela 12: Conseguiu trabalho na mesma área?

\begin{tabular}{l|l|l|l}
\hline Ordem & Questão 12 - Conseguiu trabalho na mesma área? & $\begin{array}{l}\text { Repetições } \\
\text { ou } \\
\text { incidências }\end{array}$ & Percentuais \\
\hline 01 & Não. Só após o término da faculdade. & 3 & $50 \%$ \\
\hline 02 & Sim. Poderia trabalhar em qualquer área. & 3 & $50 \%$ \\
\hline
\end{tabular}

Fonte: Dados da Pesquisa elaborada pelo Autor

Gráfico 12: Trabalho na mesma área.

\section{Repetições ou incidências}

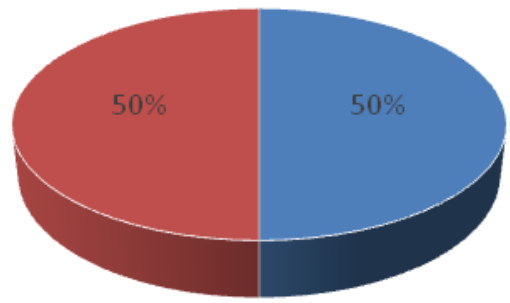

- 1 Nåo. Só após o término da faculdade.

- 2 Sim Poderia trabalhar em qualquer área.

Fonte: Elaborado pela autora, 2018.

De acordo com a tabela e o gráfico 12, assimila-se do parágrafo-síntese da décima segunda questão: "Os respondentes afirmaram que conseguiram trabalho logo após o término da faculdade e poderia atuar em outras áreas afins". No período compreendido entre os anos de 1997 e 2001, lapso temporal em que os egressos se formaram, o mercado de trabalho era bastante promissor e a demanda por contador era enorme, além disso, perspectivas profissionais estavam surgindo, a exemplo da atuação como investigador contábil, da contabilidade ecológica, da auditoria ambiental, da contabilidade prospectiva (voltada para cenários e procedimentos futuros), do empresário contábil com um novo perfil, entre outras. Nesse período também tem-se que os graduados em Contabilidade tinham um maior índice de aproveitamento nos concursos públicos em áreas afins, comparativamente a outros graduados (IÚDICIBUS; MARION, 2002).

Página 122 Caderno de Ciências Sociais Aplicadas, Vitória da Conquista/BA, vol. 16, n 27, ano 16, p. 109-129, jan/jun 2019. 


\section{Cadernos de Ciéncias SOCIAIS APLICADAS}

Tabela 13: Quando você entrou no curso, você já trabalhava? Em que função?

\begin{tabular}{l|l|l|l}
\hline Ordem & $\begin{array}{l}\text { Questão 13 - Quando você entrou no curso, você já } \\
\text { trabalhava? Em que função? }\end{array}$ & $\begin{array}{l}\text { Repetições } \\
\text { ou } \\
\text { incidências }\end{array}$ & Percentuais \\
\hline 01 & Quando ingressou no curso atuava como administrador. & 1 & $16 \%$ \\
\hline 02 & Quando ingressou no curso trabalhava em uma escola. & 1 & $16 \%$ \\
\hline 03 & Quando ingressou no curso era bancário. & 1 & $17 \%$ \\
\hline 04 & Não trabalhava. & 1 & $17 \%$ \\
\hline 05 & Quando ingressou era professora. & 1 & $17 \%$ \\
\hline 06 & Quando ingressou era digitadora. & 1 & $17 \%$ \\
\hline
\end{tabular}

Fonte: Dados da Pesquisa elaborada pelo Autor

Gráfico 13: Durante o percurso do curso, cargo exercido.

\section{Repetições ou incidências}

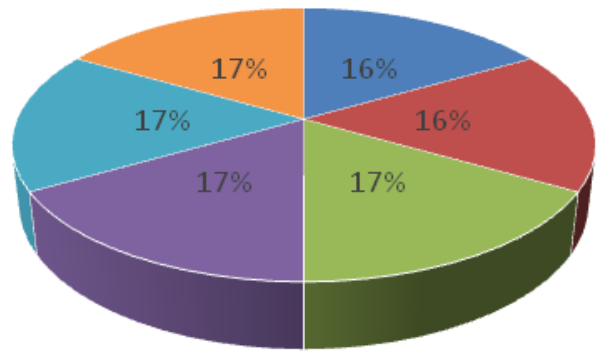

- 1 Quando ingressou no curso atuava como administrador.

- 2 Quando ingressou no curso trabalhava em uma escola.

- 3 Quando ingressou no curso era bancário.

- 4 Năo trabalhava.

- 5 Quando ingressou era professora.

- 6 Quando ingressou era digitadora.

Fonte: Elaborado pela autora, 2018.

Conforme mostra a tabela e o gráfico13, acerca da temática suscitada na pesquisa relativa ao trabalho do discente antes de iniciar o curso, tem-se que o parágrafo-síntese da décima terceira questão é o seguinte: “Os respondentes afirmaram que quando entrou no curso já trabalhava em uma área específica”. De acordo com os respondentes, eles laboraram em diversas áreas, nenhum na área de contabilidade, em escritórios ou como técnico em contabilidade.

Página 123 Caderno de Ciências Sociais Aplicadas, Vitória da Conquista/BA, vol. 16, n 27, ano 16, p. 109-129, jan/jun 2019. 


\section{- Cadernos de Ciénclas SOCIAIS APLICADAS}

Tabela 14: Em sua opinião o Curso de Ciências Contábeis oferece melhores oportunidades de emprego que os demais cursos?

\begin{tabular}{l|l|l|l}
\hline Ordem & $\begin{array}{l}\text { Questão 14 - Em sua opinião Curso de Ciências } \\
\text { Contábeis oferece melhores oportunidades de emprego, } \\
\text { que os demais cursos? }\end{array}$ & $\begin{array}{l}\text { Repetições } \\
\text { ou } \\
\text { incidências }\end{array}$ & Percentuais \\
\hline 01 & $\begin{array}{l}\text { O curso de Ciências Contábeis tem mais opções de } \\
\text { empregabilidade. }\end{array}$ & 5 & $83 \%$ \\
\hline 02 & $\begin{array}{l}\text { O profissional que se especializa nela ou que procura se } \\
\text { aprofundar nela terá um leque de opções muito grande. }\end{array}$ & 1 & $17 \%$ \\
\hline
\end{tabular}

Fonte: Dados da Pesquisa elaborada pelo Autor

Gráfico 14: Oportunidade de emprego em relação aos demais cursos.

\section{Repetições ou incidências}

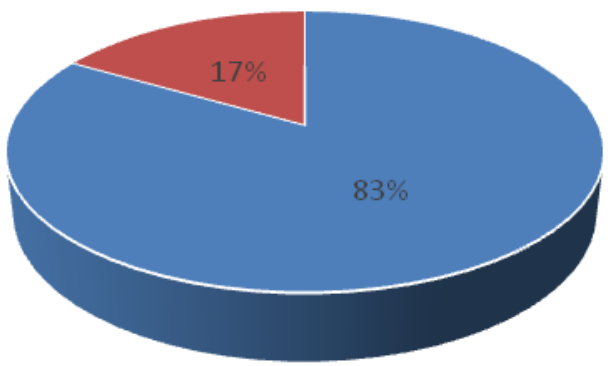

- 10 curso de Ciências Contábeis tem mais opções de empregabilidade.

O profissional que se especializa nela ou que procura se aprofundar nela terá um leque de opçóes muito grande.

Fonte: Elaborado pela autora, 2018.

De acordo com a tabela e o gráfico 14, o parágrafo-síntese da décima quarta questão é o seguinte: "Os respondentes afirmaram que o curso de Ciências Contábeis tem mais opções de empregabilidade", opiniões que registram que o curso de Ciências Contábeis oferece melhores oportunidades de emprego que os demais cursos. Apesar do destaque do referido ponto favorável, a pesquisa igualmente apreendeu que os contadores que querem se destacar e garantir empregabilidade necessitam buscar "constantemente conhecimento, atualização através de eventos, palestras e demais

Página 124 Caderno de Ciências Sociais Aplicadas, Vitória da Conquista/BA, vol. 16, n 27, ano 16, p. 109-129, jan/jun 2019. 


\section{Cadernos de Ciéncias SOCIAIS APLICADAS}

atividades relacionadas à capacitação profissional voltado para a área contábil, e devem realizar leituras constantes, para que possam ser profissionais em destaque, e serem contratados para os mais de 30 cargos oferecidos na área contábil”.

Tabela 15: Qual deve ser o perfil de um contador para que ele possa crescer profissionalmente?

\begin{tabular}{l|l|l|l}
\hline Ordem & $\begin{array}{l}\text { Questão 15 - Qual deve ser o perfil de um contador para } \\
\text { que ele possa crescer profissionalmente? }\end{array}$ & $\begin{array}{l}\text { Repetições } \\
\text { ou } \\
\text { incidências }\end{array}$ & Percentuais \\
\hline 01 & $\begin{array}{l}\text { O perfil tem que ser pautado na ética, moral e nos } \\
\text { princípios e na fundamentação, de se colocar de pé, } \\
\text { sempre na condição de empatia com o cliente. }\end{array}$ & 2 & $33 \%$ \\
\hline 02 & $\begin{array}{l}\text { Comprometimento e responsabilidade independente de } \\
\text { qual profissão, ela escolher, ela vai crescer } \\
\text { profissionalmente. }\end{array}$ & 1 & $17 \%$ \\
\hline 03 & O perfil de proativo e nunca o de reativo. & 2 & $33 \%$ \\
\hline 04 & $\begin{array}{l}\text { Competência, estar preparado, lendo, estudando, para } \\
\text { uma determinada área e a persistência que nada na vida } \\
\text { aparece de mãos beijadas, acho que essas são duas } \\
\text { características essenciais. }\end{array}$ & 1 & $17 \%$ \\
\hline
\end{tabular}

Fonte: Dados da Pesquisa elaborada pelo Autor

Gráfico 15: Perfil do profissional contábil.

Repetições ou incidências

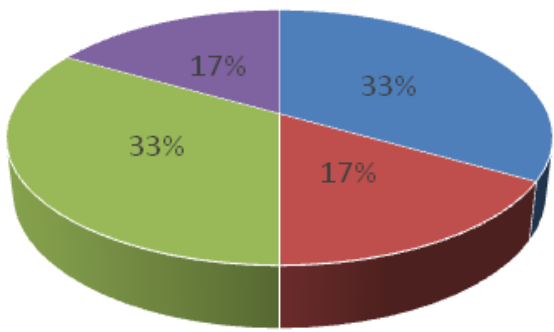

- 10 perfil tem que ser pautado na ética, moral e nos princípios e na fundamentação, de se colocar de pé, sempre na condição de empatia com o cliente.

- 2 Comprometimento e responsabilidade independente de qual profissão, ela escolher, ela vai crescer profissionalmente.

- 30 perfil de proativo e nunca o de reativo.

- 4 Competência, estar preparado, lendo, estudando, para uma determinada área e a persistência que nada na vida aparece de mãos beijadas, acho que essas são duas características essenciais.

Fonte: Elaborado pela autora, 2018.

Página 125 Caderno de Ciências Sociais Aplicadas, Vitória da Conquista/BA, vol. 16, n 27, ano 16, p. 109-129, jan/jun 2019. 
Conforme a tabela e o gráfico 15, o parágrafo-síntese da décima quinta questão é o seguinte: “O perfil do contador deve ser pautado na ética, moral e nos princípios de fundamentação, de se colocar de pé, sempre com empatia com o cliente. E sempre proativo". Ao afirmarem que o perfil do contador deve ser pautado na ética, os respondentes demonstraram que entendem bem qual é o papel da ética como ação "reguladora", como ela atua e influencia o profissional no desempenho das suas atividades, levando-o a respeitar os semelhantes no exercício de suas carreiras. Além disso, a ética envolve o relacionamento de profissionais, para resgatar a dignidade humana e a construção do bem comum. Para o desenvolvimento de uma atividade profissional, é preciso que os indivíduos que estejam envolvidos naquele contexto sigam diretrizes que regulamentam as suas profissões, sendo este também um ponto importante observado na pesquisa, relativa à atuação do profissional de ciências contábeis.

\section{Considerações finais}

Diante dos resultados alcançados com o presente estudo, foi possível responder à questão problema suscitada, bem como constatar-se que os egressos de Ciência Contábeis da UESB estão inseridos no mercado de trabalho desde o período de sua formação, sendo que atualmente, após a conclusão do curso superior, estão trabalhando na área contábil em diversas áreas, tanto na área pública, quanto na privada, atuando principalmente como professores.

O objetivo proposto na pesquisa foi alcançado, pois com base nas respostas obtidas com a amostra escolhida (06 respondentes), observou-se que o mercado de trabalho em Vitória da Conquista para o egresso de Ciências Contábeis, até a presente data, é bastante promissor e com oportunidades de atuação em diversas áreas, porquanto o profissional pode atuar em empresas públicas ou privadas, laborando como autônomo, no ensino e em órgão público.

Percebeu-se também que, apesar de dispor de abertura para o egresso, o mercado de trabalho é muito exigente e requer um profissional competente para o exercício da profissão, que possa assumir um papel de gestor da informação e utilizando seus mecanismos para interferir no processo decisório da empresa.

Para tanto, o egresso precisa se preocupar com a sua educação profissional continuada. Os egressos ouvidos no presente trabalho mostraram-se preocupados com isso e investiram em sua capacitação, seja por meio de investimentos em novas capacitações mais específicas da área, de participação em congressos e até com realização de curso de pós-graduação (mestrado) em sua área de formação acadêmica.

Página 126 Caderno de Ciências Sociais Aplicadas, Vitória da Conquista/BA, vol. 16, n 27, ano 16, p. 109-129, jan/jun 2019. 
O mercado de trabalho valoriza o profissional mais bem preparado e qualificado, e isso se reflete na remuneração do contador. Os egressos que investiram na sua qualificação profissional exprimem satisfação com a sua remuneração e as pesquisas apontam: a remuneração de um contador é compatível com o nível de escolaridade.

Com a pesquisa, percebeu-se que o profissional nunca deve abandonar o seu aprendizado, devendo sempre investir em sua capacitação profissional e intelectual, para agregar valor em si mesmo, procurando sempre ser um ótimo profissional e uma excelente pessoa com valores éticos indispensáveis, seja qual for o tempo e o espaço no qual estiver inserido.

Como sugestão, este trabalho sugere que novas pesquisas sejam empreendidas, para verificar a aceitação dos profissionais de Ciências Contábeis da UESB pelo mercado de trabalho não só de Vitória da Conquista, mas também de outras regiões.

\section{Referências}

BARDIN, Laurence. Análise de Conteúdo. Edições 70. São Paulo, 2011.

BRANDÃO, Carlos Rodrigues. O que é educação. São Paulo: Brasiliense, 2005. Ed. 46 .

DAL-CIN, Daniela. Uma Leitura Sobre a Docência na Educação Superior em Ciências Contábeis: Aproximações...EDUCERE. Artigo publicado no XIII Congresso Nacional de Educação. ISSN 21761396, Universidade Comunitária da Região de Chapecó - Unochapecó. Chapecó. p. 16853 - 16867. Disponível em: http://educere.pucpr.br/p84/anais.html?titulo=\&edicao=6. Acesso em: 30 set. 2018.

FERREIRA, Aurélio Buarque Hollanda de. Novo Aurélio século XXI: o dicionário da língua portuguesa. 3. ed. Rio de Janeiro: Nova Fronteira, 1999.

HOSS, Osni; CASAGRANDE, Luiz Fernande; DAL VESCO, Delci Grapegia; LEAL, Edvalda Araujo; SOARES, Mara Alves; SOUZA, Edileuza Godói de. Perspectivas dos formandos do curso de ciências contábeis e as exigências do mercado de trabalho. Revista Contemporânea de contabilidade. ISSN 1807-1821, UFSC, Florianópolis, ano 05, v.1, nº10, p. 147-159, Jul./Dez., 2008. Disponível em: https:/ /www.redalyc.org/articulo.oa?id=76212303008. Acesso em: 30 set. 2018.

IUDÍCIBUS, Sergio de; MARION, Jose Carlos. Introdução á teoria da contabilidade para o nível de graduação - 4. ed. reimpr.- São Paulo: Atlas, 2008.

IUDÍCIBUS, Sergio de; MARION, Jose Carlos.Introdução à Teoria da Contabilidade para o nível de graduação. 3.ed. Atlas. São Paulo 2002.

Página 127 Caderno de Ciências Sociais Aplicadas, Vitória da Conquista/BA, vol. 16, n 27, ano 16, p. 109-129, jan/jun 2019. 
LAKATOS, E. M. \& MARCONI, M. A. Metodologia do trabalho científico. $7^{\text {a }}$ ed. São Paulo: Atlas, 2006.

LOUSADA, Ana Cristina Zenha; MARTINS, Gilberto de Andadre. Egressos como Fonte de Informação à Gestão dos Cursos de Ciências Contábeis. Contabilidade Financeira. USP, São Paulo, n. 37, p. 73 - 84, Jan./Abr. 2005 Artigo originalmente apresentado no $3^{\circ}$ Congresso USP de Controladoria e Contabilidade, 2003. USP, São Paulo, 2005. Disponível em: http://www.scielo.br/pdf/rcf/v16n37/v16n37a06.pdf. Acesso em: 02 nov. 2018.

LAFFIN, Marcos. De contador a professor: a trajetória da docência no ensino superior de contabilidade. 2002. 203 f. Tese (Doutorado em Engenharia de Produção) - Universidade Federal de Santa Catarina, Florianópolis, 2002.

LAFFIN, Marcos. De contador a professor: A trajetória da docência no ensino superior de contabilidade. Imprensa Universitária. UFSC. Florianópolis, 2005.

LOPES, J. O fazer do trabalho científico em ciências sociais aplicadas. Recife: UFPE, 2006.

MARCONI, Marina de Andrade; LAKATOS, Eva Maria. Fundamentos de Metodologia Científica. 5. ed. São Paulo: Atlas, 2003.

MARION, José Carlos Contabilidade empresarial. 11 ed. São Paulo: Ed. Atlas S.A, 2005.

MARION, José Carlos. Contabilidade Empresarial. 13. ed. - São Paulo: Atlas, 2007.

MARTINS, Ronei Ximenes. Metodologia de Pesquisa guia de Estudos. UFLA 2013.

OLIVEIRA, H. M.; SILVA, J. O. Perfil do profissional contábil: Um estudo de suas habilidades. In: CONGRESSO UFSC DE CONTROLADORIA E FINANÇAS \& INICIAÇÃO CIENTÍFICA EM CONTABILIDADE. 5, 2014, Florianópolis. Anais eletrônicos... Florianópolis: UFSC, 2014. Disponível em: http://dvl.ccn.ufsc.br/congresso/arquivos_artigos/artigos/1044/20140425105314.pdf. Acesso em: 30 fev. 2017.

PEREIRA, Thomas Augusto Alves. A ética contábil no cotidiano do profissional contabilista. 2017. Trabalho de Conclusão de Curso (Bacharelado em Ciências Contábeis). Universidade Estadual do Sudoeste da Bahia, Vitória da Conquista, 2018. Disponível em: http://www2.uesb.br/cursos/contabeis/wp-content/uploads/MONOGRAFIA-THOMASAUGUSTO-2017.pdf. Acesso em: 30 set. 2018.

RICHARDSON, Roberto Jarry. Pesquisa social: métodos e técnicas. 3 ed. São Paulo: Atlas, 1999.

Página 128 Caderno de Ciências Sociais Aplicadas, Vitória da Conquista/BA, vol. 16, n 27, ano 16, p. 109-129, jan/jun 2019. 


\section{- CADERNos de CIIENCIAS SOCIAIS APLICADAS}

SANTOS, M.L.; SOUZA, M.A. A importância do profissional contábil na contabilidade gerencial: uma percepção dos conselheiros do CRC/MG. Revista Científica do Departamento de Ciências Jurídicas, Políticas e Gerenciais do UNI-BH, vol.3, n. 1. Belo Horizonte, 2010. Disponível em: http://revistas.unibh.br/index.php/dcjpg/article/view/56. Acesso em: 20 de mar. 2017.

SILVA, César Augusto Tibúrcio. Contabilidade Geral. Florianópolis: Departamento de Ciências da Administração / UFSC; [Brasília]: CAPES: UAB, 2009.

SILVA, Thiago Prates. Teoria da contabilidade: Percepção de Alunos e Professores da Graduação em Ciências Contábeis. 2018. Trabalho de Conclusão de Curso (Bacharelado em Ciências Contábeis). Universidade Estadual do Sudoeste da Bahia, Vitória da Conquista, 2018. Disponível em: http://www2.uesb.br/cursos/contabeis/wp-content/uploads/Monografia-Ajustada.pdf. Acesso em: 26 set. 2018. 